\title{
Breast milk versus formula milk and neuropsychological development and sleep
}

\author{
Volume I Issue I - 2014 \\ Tamer Mohamed Gaber Rizk \\ Department of Pediatrics, Al-Takhassusi Hospital, Saudi Arabia \\ Correspondence: Tamer Mohamed Gaber Rizk, Department \\ of Pediatrics, Al-Takhassusi Hospital, Dr. Suleiman Al-Habib \\ Medical Group (HMG), Riyadh, Saudi Arabia, Tel 966I I-283- \\ 3733, Fax 966 I I-283-3033, Email tamergaber2@yahoo.com \\ Received: April 14, 2014 | Published: May 16, 2014
}

feeding is much advantageous for neuro-behavioral development and organization of infants. ${ }^{4}$

Minimal duration of breast feeding, or exclusive breast feeding duration that will be needed to provide optimal neuro-behavioral and neuro-psychological outcomes for the newborns was previously investigated through assessing the quality of motor development of neonates. A directly proportional relationship was confirmed between breastfeeding duration and quality of movement especially for the first 6 weeks of life. Infants who were exclusively breastfed for the first 6 weeks of life were found to have optimal gross motor milestones in $47 \%$, compared to $18 \%$ in the group of neonates who were breast fed for less than 6 weeks. ${ }^{5,6}$

Follow up randomized studies in Honduras for breast fed infants for 4 months and older showed that exclusive breast feeding for 6 months was linked to better developmental milestones acquirement than introducing solid food. In addition to breast feeding from the fourth month, they crawled sooner and was more likely to walk by a maximum of 12 months, than other infants who were exposed to solid food since the age of 4 months even in addition to breast feeding. ${ }^{7}$

Exclusive breast feeding should always be encouraged and variable benefits to neonates and infants to be delivered to their caregivers, motor development, myelination pattern are just examples to breast milk benefits which extend to include better sleeping pattern, psychosocial development as well as other critical areas of early infant development.

\section{Acknowledgments}

None. the study showed that breast fed infants exhibited fewer abnormal reflexes, signs of depression, and withdrawal. This proves that breast outcome feeding should be encouraged for best neuro-developmental was done for 83 neonates at their ninth day of life, though special assessment scale "Brazelton Neonatal Behavioral Assessment Scale". 


\section{Conflicts of interest}

The authors have no conflict of interests related to this publication and have not received any grants.

\section{Funding}

None.

\section{References}

1. Sacker A, Quigley MA, Kelly YJ. Breastfeeding and developmental delay: findings from the millennium cohort study. Pediatrics. 2006;118(3):e682-e689.

2. Khedr EM, Farghaly WM, Sel-D A, et al. Neural maturation of breastfed and formula-fed infants. Acta Paediatr. 2004;93(6):734-738.

3. Morley R, Fewtrell MS, Abbott RA, et al. Neurodevelopment in children born small for gestational age: a randomized trial of nutrient-enriched versus standard formula and comparison with a reference breastfed group. Pediatrics. 2004;113 (3 Pt 1; 515-521.
4. Hart S, Boylan LM, Carroll S, Musick YA, et al. Brief report: breastfed one-week-olds demonstrate superior neurobehavioral organization. J Pediatr Psychol. 2003;28(8):529-534.

5. Bouwstra H, Boersma ER, Boehm G, et al. Exclusive breastfeeding of healthy term infants for at least 6 weeks improves neurological condition. J Nutr. 2003;133 (12):4243-4245.

6. Dewey KG, Cohen RJ, Brown KH, et al. Effects of exclusive breastfeeding for four versus six months on maternal nutritional status and infant motor development: results of two randomized trials in Honduras. J Nutr. 2001;131(2):262-267.

7. Vestergaard M, Obel C, Henriksen TB, et al. Duration of breastfeeding and developmental milestones during the latter half of infancy. Acta Paediatr. 1999;88(12):1327-1332. 